\title{
HARIDUSALASTE TEKSTIDE VÕRDLEV DISKURSUSANALÜÜS
}

\section{Katrin Aava}

Ülevaade. Artiklis uuritakse ühiskonnas makrotasandil domineerivaid ideoloogiaid mikrotasandil haridusalastes tekstides esinevate diskursuste kaudu. Võrreldakse Eesti, Sloveenia ning Soome tähtsamate haridusalaste tekstide - õppekavade ning haridusseadustike - hariduspoliitilisi diskursusi, et mõista nende rolli sotsiopoliitilises kontekstis. Otsitakse vastust küsimustele, kuivõrd on esindatud sotsiaaldemokraatlik, liberaalne ja konservatiivne diskursus, milliseid sarnasusi, erinevusi ja muutusi võib eri ühiskondades täheldada, kuidas diskursused on ajas muutunud. Tulemusi võrreldakse sotsiaalteadlaste ning haridusalaste diskursusanalüüsijate käsitlustega.

Võtmesõnad: kriitiline diskursusanalüüs, õppekava, haridusseadustik, ideoloogia, eesti keel, soome keel, sloveenia keel

\section{Diskursus ideoloogia väljendajana}

Diskursus, keelekasutus ja kommunikatsioon mängivad olulist rolli ideoloogia taastootmisprotsessis. Teun van Dijki (2005: 41-57) järgi väljendub või jõustub ideoloogia sümbolite, rituaalide, diskursuste või muude sotsiaalsete ja kultuuriliste praktikate kaudu. Ideoloogia kontrollib grupi arvamusi, hoiakuid ja teadmist, sest grupile eriomane teadmine võib väga hästi olla seotud grupi huvide või muude omadustega ning olla kaasatud konkurentsi, võitlusse või domineerimisse. Ideoloogia on üldiste sotsiaalsete uskumuste kogum, mis on grupi uskumuste aluseks. Sotsiaalsete uskumuste kognitiivse eritlemise asemel võime teha sarnaseid eristusi diskursustes, mis väljendavad või konstrueerivad sotsiaalseid uskumusi.

Kool ja haridussüsteem tervikuna kuuluvad kõige keerukamate ja tõhusamate ideoloogiliste institutsioonide hulka juba sel põhjusel, et nad hõlmavad peaaegu kõiki ühiskonna liikmeid intensiivselt ja iga päev, vahel isegi kauem kui 20 aastat. Nii toimib haridussüsteem ühiskonnas domineerivate ideede ning ideoloogiate taastootmise põhivahendina (van Dijk 2005: 221). Seetõttu on oluliste haridus- 
alaste tekstide puhul nagu õppekava ning haridusseadustik vaja teada, millistest ideoloogilistest veendumustest nad on kantud ning milliseid ideoloogilisi uskumusi nad taastoodavad. Kuna ideoloogiaid ei väljendata haridustekstides otsesõnu, tuleb minna gruppide ja institutsioonide sotsiaalsest makromaailmast mikrotasandile ehk sellele tasandile, kus sotsiaalsed agendid sotsiaalsetes situatsioonides ideoloogiaid tegelikult toodavad ning uurida diskursusi (van Dijk 2005: 58-59).

Diskursused "lihtsustavad" või "tõlgivad" majanduslikke ning poliitilisi suhteid. Millistel võistlevatel diskursustel (narratiividel, kujutlustel), millistel strateegiatel õnnestub end kehtestada, sõltub Norman Fairclough' (2005: 55-56) meelest muu hulgas järgmistest asjaoludest:

1) "strukturaalne valikulisus" - T. van Dijki (2005: 275) hinnangul võivad suhtlusvaldkonna kategooriad, tegutsemise tüüp ning asjaolud olulisel määral soodustada ideoloogia taastootmist: mõni valdkond on strateegiatele rohkem avatud kui teine. Näiteks klassiruumis ja haridussüsteemis, parlamendis ja poliitikas, uudistetoimetuses ja meedias soodustab ideoloogia levikut sotsiaalsete agentide usutavus ning prestiiž, samuti teksti massivahendamise tagajärjed;

2) diskursuse ulatus - nt "globaliseerumise" ning "teadmistepõhise majanduse" diskursust võib vaadelda kui üht tüvidiskursust, mille põhjal sõnastatakse mitmed muud diskursused (nt "elukestva õppe diskursus");

3) sotsiaalsete agentide jõud ning võimekus kehtestada oma diskursus, nende võimalus kaasa rääkida massimeedias ja teadvustööstuses;

4) diskursuse resonants - s.t võime kaasata lisaks inimestele ka institutsioone.

Nendele tingimustele vastavad haridusalased tekstid väga hästi. Siinse uurimuse eesmärk ongi uurida ühiskonnas domineerivaid ideoloogiaid haridusalastes tekstides võrdlevalt kolmel maal: Eestis, Soomes ja Sloveenias. Kuna ideoloogilisi uskumusi otseselt haridustekstides ei väljendata, siis saab neid uurida diskursuste kaudu. Ühes haridusalases tekstis võib leida märke erinevatest diskursustest, sest ühiskonna huvigrupid, kes tekste toodavad, võistlevad oma ideoloogia kehtestamise nimel.

Käesolevas analüüsis on vaatluse all kolm kõige selgemini eristatavat poliitilist ideoloogiat - sotsialism, konservatism ja liberalism - ning nende tänapäevased edasiarendused. Kuna Euroopas on esindatud eelkõige kolme tüüpi poliitilisi parteisid: liberaalsed (uus-liberaalsed), konservatiivsed (uuskonservatiivsed) ning sotsialistlikud (sotsiaaldemokraatlikud, kolmas tee), siis on analüüsis lähtutud eeldusest, et just need kolm on valitsevad poliitilised ideoloogiad.

\section{Eesti, Soome ja Sloveenia haridustekstide diskursusanalūứs}

Eesti ja Soome haridustekstid on kultuuriliselt ning geograafiliselt lähedased, tegemist on soomeugri keeleruumiga. Samuti on oluline, et iseseisvumise järel on Eestil tihedad haridusalased kontaktid just eduka Soomega. Samas on Eesti ja Sloveenia ajalugu sarnasem, mõlemad riigid taastasid iseseisvuse 1991. aastal, kuuludes eelnevalt Nõukogude Liidu mõjusfääri. Huvitav on ka asjaolu, et Sloveenia ühines Euroopa Liiduga samal ajal kui Eesti. Uuring võimaldab võrrelda Eesti 
haridusalast diskursust kahe Euroopa Liidu riigiga, ülieduka Soome ning kiire arenguga Sloveeniaga.

Analüüsis otsitakse vastust küsimustele, kuivõrd on esindatud sotsiaaldemokraatlik, liberaalne ja konservatiivne diskursus, milliseid sarnasusi, erinevusi ja muutusi võib eri ühiskondades täheldada, kuidas diskursused on ajas muutunud. Tulemusi võrreldakse sotsiaalteadlaste ning haridusalaste diskursusanalüüsijate käsitlustega, eelkõige sotsiokultuuriliste muutuste ja diskursiivsete muutuste suhte analüüsi suuna peaesindaja Norman Fairclough' $(1992,1999,2005)$ seisukohtadega.

\subsection{Meetod}

Meetodina on kasutatud sõnaanalüüsi (Dijk 2005) ja programmi WordSmith Tools (Scott 1997). Leksikaalne analüüs on T. van Dijki (2005: 244) hinnangul kõige enesestmõistetavam (ja ikka veel viljakas) diskursuse ja ideoloogilisuse analüüsimise komponent. Seetõttu on töös lähtutud eeldusest, et ideoloogiliste muutustega peavad kaasnema muutused ka keelekasutuses ning sõnavaras. Töö toimus järgnevalt.

Arvutisse sisestati Eesti, Soome ning Sloveenia lasteaedade, üldhariduskoolide kehtivate õppekavade ning haridusseadustike tekstid.

Töögrupp (haridussotsioloogid Slavko Gaber, Klemen Slabina, Veronika Tasner) valis esmalt märksõnad teoreetilise kirjanduse põhjal (Kymlicka 2002, Waldron 1993, Nisbet 1978). Märksõnad tõlgiti kolme keelde ning kontrolliti nende konteksti. Programm võimaldab sisestada haridustekstidesse sõnatüved. Töögrupp (Katrin Aava, Anne Lindström, Pille Riismaa, Klemen Slabina) jättis analüüsist välja a) sõnad, mis üldiselt ei esinenud ideoloogiliselt tähenduslikus kontekstis, b) sõnad, mille tüvi ei eristunud teiste sõnade tüvedest.

Kuna sotsiaaldemokraatliku ideoloogia sõnu oli kõige vähem, nimelt 15, eraldati igast grupist 15 sagedamini esinevat sõna. Nii moodustusid võrdse suurusega sõnagrupid. Ühtlasi võimaldas see vabaneda ballastist, nt konservatiivses plokis jäi Eesti puhul välja sõna sloveenia ja vastupidi. Seejärel liideti 15 sõna kogusumma ning jagati see õppekavades haridusseadustikus olnud sõnade arvuga. Seega väljendab tulemus ideoloogiliselt markeeritud sõna osakaalu kogu tekstist. Esimese 15 sõna arv on jagatud kogu tekstis esinenud sõnade arvuga, et saada võrreldavad tulemused.

Programm WordSmith Tools võimaldas sisestada sõnatüvesid, aga siin on lugemise hõlbustamiseks esitatud mitte tüved, vaid sõnavormid viisil, et väljenduks nende ideoloogiline tähendus.

Sotsiaaldemokraatlikku ideoloogiat väljendatakse diskursusega, kus esineb järgmisi sõnu: töötaja, teenindama, hool, erivajadus, koostöö, sotsiaal, olukord, konflikt, partner, kohanema, heaolu, konsensus, läbirääkimised, solidaarsus, ametiühingud.

Liberaalset ideoloogiat väljendatakse diskursusega, kus esineb sõnu: õigused, standardid, kodanik, loov, valik, privaat, väärikus, võõrkeel, individuaalne, mitmekesisus, erinevus, võõras, alternatiiv, avatus, sallivus, elustiil, talent, elusfäär, võimekus, kaubandus, paindlikkus.

Konservatiivset ideoloogiat saab iseloomustada diskursusega, kus võib leida sõnu või sõnatüvesid: eesti, vene, soome, Rootsi, Sloveenia, rahvas, rahvus, pere, kodu, rahva-, etno-, eetika, traditsioon, religioon (ka usk ning uskumus), ema, autoriteet, lojaalsus, sanktsioonid, karistus. 
Problemaatiline oli, et eri maade tekstid olid väga heterogeensed. Samuti olid haridusseadused väga erineva mahuga: kui Eesti tekstis oli 3695 sõna, siis Soome omas 13936 ning Sloveenia omas 17447 sõna. Kui Eesti õppekavades oli kokku 68325 sõna, siis Soomes 119779 ning Sloveenias 410829 sõna. Seetõttu on uuringute aluseks võetud keskmine ehk esinenud märksõnade arv jagati kogu teksti sõnade arvuga.

Kõige mahukamas tekstis (Sloveenia õppekava) on kõige vähem loendisse valitud ideoloogiliselt markeeritud märksõnu. Kui võrrelda kõige mahukamat (Sloveenia) teksti kõige lühema (Eesti) tekstiga, siis siin on erinevused oluliselt väiksemad, kui kahe mahukama, Soome ja Sloveenia teksti vahel (vt joonis 1). See julgustab siiski tulemusi võrdlema, hoolimata erinevast sõnade arvust.

Samuti tekitas küsitavusi asjaolu, kas valitud märksõnad võimaldavad teha järeldusi ideoloogiate esinemise kohta. Samas aga tulemused ühtivad paljuski kriitilise diskursusanalüüsi teoreetikute seisukohtadega, kelle hinnangul sotsiaaldemokraatlik ideoloogia on taandumas ning konservatiivne tõusuteel. See asjaolu lubab teha järeldusi kolme maa haridustekstide kohta.

\subsection{Haridustekstide võrdluse tulemused}

Tulemuste võrdlemine maade kaupa näitab, et õppekavade vahel joonistuvad välja suuremad erinevused kui haridusseadustes (vt joonis 1). Eesti ning Soome õppekava on valitud ideoloogiliste märksõnade võrdluses lähedasemad, suuremad erinevused on Soome ning Sloveenia õppekavade vahel, haridusseadustikke võrreldes erineb Eesti oluliselt rohkem Soome ja Sloveenia tekstidest.

Soome haridusseaduses, mis on kõige vanem tekst, on sotsiaaldemokraatlik diskursus kõige rohkem esindatud. Näiteks sõnatüvi hool* esineb 99 korda ehk moodustab lausa $0,71 \%$ kogu teksti sõnadest. Samuti on sotsiaaldemokraatlik diskursus jõuliselt esindatud Sloveenia haridusseadustes: näiteks moodustab sõna erivajadused 0,36\% kogu sõnade arvust.

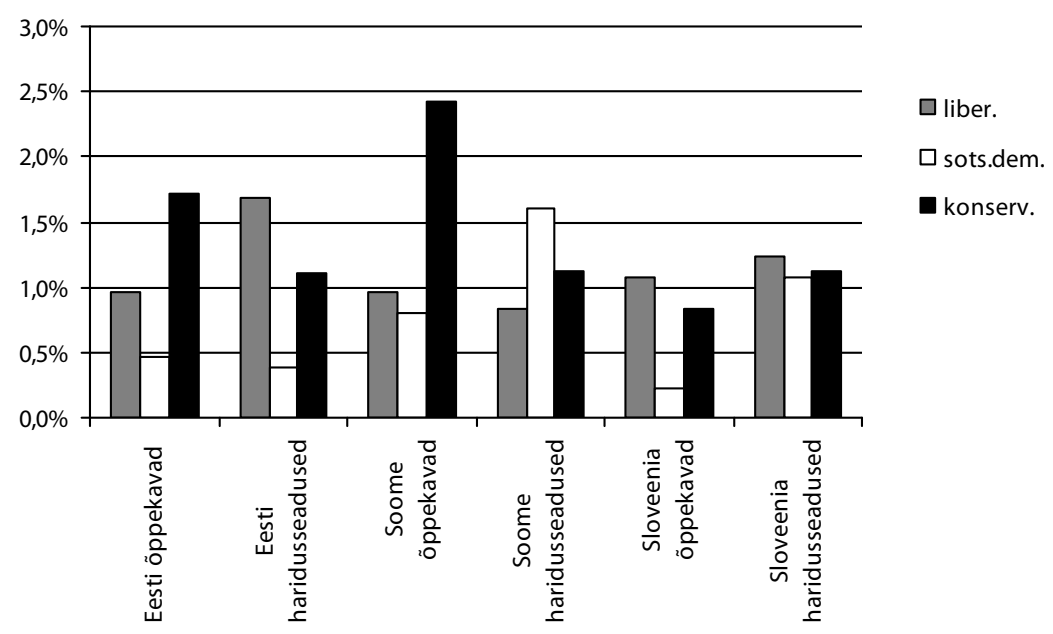

Joonis 1. Haridustekstide võrdlus maade kaupa. Esitatud ühe ideoloogilise märksõna osakaal tekstis 
Kolme maa haridustekste võrreldes (vt joonis 1) tuleb esile see, et Eesti ja Sloveenia haridustekste iseloomustab tugev liberaalse diskursuse osakaal. Soome haridustekstides tõusevad Eesti ning Sloveeniaga võrreldes esile pigem sotsiaaldemokraatlik, aga ka konservatiivne diskursus. Soome õppekava eristub ka selle poolest, et sõnad usk, aga ka uskumu*, religioon esinevad Eesti õppekavas o,o1\%; Sloveenia õppekavas 0,11\% ning Soomes 0,44\%. Soome haridusseadustikus on need sõnad samuti rohkem esindatud - $0,43 \%$.

Oluliseks kujunes ka see, kui palju räägiti oma maast, keelest ning kultuurist: Eesti õppekavades 0,65\% ning seaduses 0,78\%, Soome õppekavades 0,73\% ning seaduses ainult $0,10 \%$, Sloveenia haridusseadustikus $0,38 \%$ ning seaduses $0,49 \%$.

Kolme maa haridustekstide võrdlemisel mängib olulist rolli haridusteksti valmimise aeg (vt tabel 1). Tulemused näitavad, et teksti redigeerimise aeg ei mõjuta tulemusi, sest redigeerimisel muudetakse üldteksti vähe.

Tabel 1. Õppekavade ja haridusseadustike kinnitamiste ning redigeerimiste ajad

\begin{tabular}{|l|c|c|}
\hline \multicolumn{1}{|c|}{ Õppekavad } & Kinnitatud & Viimati redigeeritud \\
\hline Eesti & & 2006 \\
\hline Lasteaedade kava & 1999 & 2006 \\
\hline Põhikool ja gümnaasium & 2002 & \\
\hline Soome & & \\
\hline Lasteaedade kava & 2000 & \\
\hline Põhikool & 2004 & \\
\hline Gümnaasium (sm lukio) & 2003 & \\
\hline Sloveenia & & \\
\hline Bela Kniga (üldosa) & 1995 & 2006 \\
\hline Ainekavad & 1998 & \\
\hline Haridusseadus & & 2006 \\
\hline Eesti & 1992 & 2003 \\
\hline Soome & & \\
\hline Lasteaed & 1973 & \\
\hline Põhikool & 1998 & \\
\hline Gümnaasium (lukio) & 1998 & \\
\hline Sloveenia & 1996 & \\
\hline Lasteaed & 1996 & \\
\hline Põhikool & & \\
\hline Gümnaasium & & \\
\hline
\end{tabular}

Kui jälgida diskursuste muutumist ajas (vt joonis 2), siis varasemates tekstides, nagu Soome ning Sloveenia haridusseaduses, on sotsiaaldemokraatliku ideoloogia märksõnu rohkem kui hilisemates haridustekstides. Soome haridusseadused on kõige vanemad tekstid ning seal domineerib veel tugevalt sotsiaaldemokraatlik diskursus. Sotsiaaldemokraatlik diskursus on ühtlasi kõige vastuolulisem. Nii Soome kui ka Sloveenia haridustekstides on sotsiaaldemokraatlik diskursus nõrgenemas, Eesti tekstide puhul see ei kehti. Sloveenia haridustekstides on see muutus väga drastiline: 1996. aastal valminud oppekavade ning 1998. aastal valminud ôppekavade (üldosa valmis juba 1995. aastal) vahel on suur erinevus.

Kui üldistada tulemusi ajalises dimensioonis, siis liberaalne diskursus on nõrgenemas ning konservatiivne diskursus tugevnemas (vt joonis 2). Liberaalne diskursus on nõrgenemas selgelt Eesti ning samuti ka Sloveenia haridustekstides. 
Hilisemates tekstides, nagu Eesti ning Soome õppekavad, on esile tõusnud konservatiivne diskursus.

Seega võib just aja dimensiooni pidada üheks olulisemaks ning huvitavamaks karakteristikuks, sest diskursused muutusid oluliselt kümnendi vältel, kajastades sedasi ideoloogilisi muutusi ühiskonnas. Selleks, et mõista kolme maa haridustekstides esinevaid diskursusi, on oluline analüüsida tulemusi laiemas rahvusvahelises kontekstis.

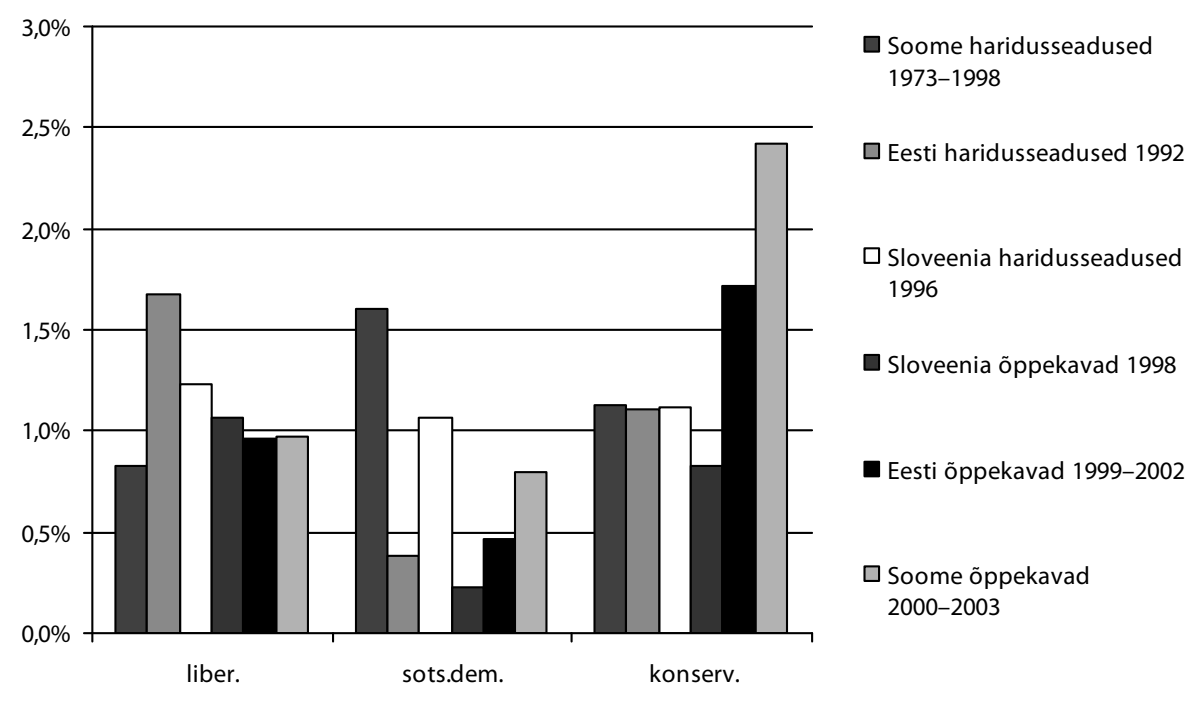

Joonis 2. Eri maade haridustekstides liberaalsete, sotsiaaldemokraatlike ning konservatiivsete märksõnade esinemissageduse võrdlus tekstide valmimise järjekorras (aluseks on varaseima teksti ilmumise aasta)

\section{Haridus majanduslike ning poliitiliste huvigruppide mõjusfääris}

Diskursused mängivad olulist võtmerolli jätkuvas globaliseeruvas maailmas konstrueerides ning legitimeerides post-heaoluühiskondade poliitikat. Muutused, mis leidsid aset 1990-ndate hariduspoliitikas, olid tihedalt seotud jõuliste ideoloogiliste suunamuutustega rahvusvahelises keskkonnas. Seega on Eesti, Soome ning Sloveenia haridustekstide analüüsimisel oluline neid ideoloogilisi muutusi ka jälgida ning võrrelda tulemusi sotsiaalteadlaste ning diskursuseuurijate seisukohtadega.

Töös analüüsitud tekstide põhjal võib märgata sotsiaaldemokraatliku diskursuse nõrgenemist. Samas just solidaarsuse, sotsiaalse õigluse ning võrdsuse ideed said aluseks lääne heaolu ühiskonnale, mis arenes II maailmasõja järel Keynes’i ideede kohaselt. Selline heaoluühiskonna elumudel, mis tagas kodanikele sotsiaalhoolekande teenused, tasuta hariduse, stabiilse pensioni, kestis kuni 1980-ndate majanduskriisini. (Giddens 1998: 9-19)

Nendest ideedest kantud sotsiaaldemokraatliku ideoloogia mõjuga võib seletada Soome haridusseadustike (lasteaedade haridusseadus lausa 1973. aastast) teistest tekstidest oluliselt tugevamat sotsiaaldemokraatlikku diskursust. Sloveenia õppe- 
kavas ning eelkõige Eesti haridustekstides on see kõige vähem esindatud diskursus, kuna Sloveenia ning Eesti ei kuulunud II maailmasõja järgse lääne demokraatliku heaoluühiskonna ideoloogilisse mõjusfär̈i.

Sotsiaaldemokraatlik diskursus on aga nõrgenenud Soome haridustekstides ning hilisemates õppekavades tõusevad esile nii liberaalne, eriti aga konservatiivne diskursus. Nimelt tunnistavad Soome uurijad (Kivirauma jt 2003), et uusliberaalse poliitika surve all on ka hariduspoliitika teinud järeleandmisi vabaturumajanduse eeskujul, lähtudes võistluse, kliendi valikuvabaduse, sponsorluse ideedest, vähendades riiklikku sekkumist. Seetõttu on toimunud diskursiivne muutus kodanikuühiskonnast individualismi suunas. Arvestades globaalset konkurentsi ning seades eesmärgiks majandusliku edukuse ning efektiivsuse, oodatakse ka haridusasutuselt konkurentsivõimelist haridust ning eelkõige tipposkusi. Kui sotsiaaldemokraatliku ideoloogia põhimõtetest lähtuv traditsiooniline ühtluskool haris kodanikke modernse ühiskonna kollektiivsetest väärtustest lähtudes, siis postmodernne indiviid arendab oma individuaalseid võimeid.

Analüüsis oluliselt jõulisemalt esindatud liberaalne diskursus on võtnud erinevate teoreetikute hinnangul uusliberaalse kuju. N. Fairclough' (1999: 75) arvates muutub globaalse kapitalismi tingimustes senisest domineerivamaks majandust kontrollivate mõjuvõimsate huvigruppide uusliberaalne ideoloogia. Uusliberalism pole neutraalne, tehnitsistlik ega majanduslik diskursus.

Uusliberaalne retoorika räägib maksimaalsest efektiivsusest, kiirest majanduskasvust ning innovatsioonist, lubades kiiresti kasvavat heaolu neile, kes soovivad kõvasti tööd teha ning olemasolevaid võimalusi kasutada. Uusliberaalne ideoloogia rakendab hariduse ärihuvide teenistusse, mis väljendub näiteks selles, et hariduse puhul on võetud kasutusele ärimaailmast pärit turundamis- ning rahastamisprintsiibid. Seda põhjustab ühelt poolt asjaolu, et finantsmajanduse areng on olnud suhteliselt konservatiivsest haridusest kiirem, surudes sedasi peale oma reeglid. Seda näitab ka asjaolu, et globaalse hariduspoliitika kujundajad on suuresti rahvusvahelised majandusorganisatsioonid. (Giroux 2004)

Seega tuleb eraldi käsitleda liberaalse ideoloogia arenguid globaliseeruvas maailmas. 1970-ndate majanduskriis toob 1980-ndatel kaasa neoliberaalse pöörde. Piisavalt kõlapinda leidis parempoolsete argument, mille kohaselt liigpalju võrdsust vähendab ettevõtlikkust ning seeläbi majanduskasvu. Praktikas avaldus see eelkõige võitluses kõrgete maksude vastu. Algas võitlus ametiühingute vastu, esile tõsteti individualistlikke väärtusi, kujunesid välja uued korporatiivsed traditsioonid ning süvenes kihistumine. Uusliberaalne poliitika tähtsustas indiviidi vastutust, rääkides heaolust, mida riik pigem võimaldab, aga mitte ei garanteeri oma kodanikule. Seega eeldatakse, et inimesed suunavad ja finantseerivad ise oma koolitust ning komplekteerivad ning ohjavad oma "haridusportfelli". (Miliband 2005: 40-41)

Üleminekuühiskonnad Eesti ja Sloveenia sattusid omariiklust ehitama hakates jõuliselt liberaalse ideoloogia mõjusfääri. Kommunistliku režiimi kokkukukkumine muutis tugevamaks liberaalsete argumendi, mille kohaselt riiklik majanduse reguleerimine toob kaasa majandusliku stagnatsiooni (Miliband 2005: 41). Sellega võib põhjendada Eesti ja Sloveenia õppekavade oluliselt jõulisemat liberaalset diskursust võrreldes sotsiaaldemokraatliku diskursusega. Uusliberaalne hariduspoliitika väljendus detsentraliseerimise, dereguleerimise, turumajanduse, suureneva valikuvabaduse retoorikas, õpetajast hakati rääkima kui teenusepakkujast, klienditeenindajast. Eestis avaldus see ka nn pearaha süsteemi kaudu, mis sundis 
haridusasutusi äriühingutena võistlema nii õpilaste kui paremate majandamistingimuste pärast.

Haridustekstide võrdlemisel võib väita, et just ajamõõdet silmas pidades muutub tugevamaks konservatiivne ideoloogia, eriti märkimisväärne on see Soome ja Eesti õppekava puhul, mis on ka hilisemad tekstid. See ühtib paljuski kriitilise diskursusanalüüsi autoritega (Fairclough 1992, Dijk 2005), kelle hinnangul 1990-ndate lõpus oli tugev uusliberaalse ideoloogia mõju (siinses töös näitavad seda Eesti ning Sloveenia haridustekstid), aga uuel sajandil võib rääkida konservatiivse ideoloogia tugevnemisest (siin tõestavad seda tendentsi Eesti ning Soome õppekavad).

Liberaalse ning konservatiivse ideoloogia seostele on tähelepanu pööranud mitmed autorid, osutades asjaolule, et uuemad konservatiivsemad hoiakud on paljuski mõjutatud liberaalsetest väärtustest. A. Giddens (1998: 8) defineerib uuskonservatismi ehk thatcherismi, mis väärtustab "õhukest” riiki, turufundamentalismi ja traditsioonilist rahvuslust, aga ei pea probleemiks ei ebavõrdsust ühiskonnas ega madalat ökoloogilist teadlikkust.

Kriitilise diskursusanalüüsi peavoolu esindajatel on erinevate ideoloogiate suhetest erinev arusaam. Kui lähtuda T. van Dijki (2005: 335) hinnangutest, siis on konservatism pigem katus- või metaideoloogia, mis korrastab teisi ideoloogiaid. Näiteks kui seda rakendada neoliberaalsetele ideoloogiatele poliitilise majanduse vallas, propageerivad konservatiivsed ideoloogiad tüüpiliselt riigi piiratud rolli turul. Sarnaselt, rakendatuna kultuurilistele ideoloogiatele, võivad konservatiivsed metaprintsiibid esineda kahes üksteist täiendavas versioonis: piiratud riigipoolse sekkumisena mõnda kultuurivaldkonda (haridussüsteemi, meediasse, religiooni) või aktiivne riigi sekkumine, näiteks jäikade seaduste kujul neis valdkondades, milles võib tekkida oht moraalsele korrale (pereväärtused, seksuaalsus, multikulturalism).

Samuti aitab konservatiivse ideoloogia esiletõusu põhjendada U. Becki (2005: 126-127) seisukohtadega. Tema hinnangul on kaasaegne euroopastumise mudel toonud meid paradoksaalsesse olukorda: euroopastunud turg, aga ka ühiskondade areng ise tingib uusrahvusluse esiletõusu. Kui 1990-ndate poliitiline võiduvalem oli uusliberaalne majanduspoliitika ning autoritaarne sisepoliitika (võõraste sissetuleku piiramine), siis uus võiduvalem võib olla autoritaarne sisepoliitika kombineeritud uusrahvusliku majandus- ja sotsiaalpoliitikaga. Mis tähendab U. Becki sõnul seda, et kaitstakse oma maa töötajate kõrgemaid palku vaesemate Euroopa Liidu töötajate eest. Ning ka sotsiaaldemokraatlikud parteid ei jää ses küsimuses immuunseks. Seega oleks üks võimalus uuritud haridustekstide tulemuste analüüsimisel järeldada, et uusliberaalne ideoloogia on kaasa toonud ka konservatiivsete väärtuste tõusu.

N. Fairclough' (1992: 9) hinnangul on haridusdiskursus koloniseeritud uusliberaalse ning uuskonservatiivse diskursuste poolt, mille tulemusena on haridusdiskursus jätkuvalt turumajanduse mõjusfääris. Globaliseeruvas maailmas konstrueeritakse ning legitimeeritakse diskursuste kaudu post-heaoluühiskondade poliitikat. Nimelt on elukestva õppe ning post-heaoluühiskonna hariduslikud agendad omavahel tihedalt seotud. Haridus mängib rahvusriikides olulist rolli sellise sotsiaalpoliitika kujundamisel, mis vähendaks valitsuse koormat ühiskondlike kohustuste täitjana (Mulderrig 2003: 4).

Samas jäävad kolme maa haridustekstide võrdlemisel mõned küsimused, mida teoreetilise kirjanduse põhjal ei oska seletada. Näiteks erinevalt teistest maadest 
on Eestis sotsiaaldemokraatlik diskursus mõnevõrra tõusnud, kuigi teiste maade kogemuse põhjal sama diskursus nõrgenes. Küsimusi tekitab ka ootamatult suur erinevus sotsiaaldemokraatliku diskursuse märksõnade vahel Sloveenia õppekavas (valminud aastatel 1995-1998) ning haridusseadustikus (valminud 1996. aastal). Samuti erineb üldisest suundumusest Sloveenia õppekava, kus konservatiivsete märksõnade diskursus on mõnevõrra nõrgenenud. Nendele küsimustele siin kasutatud metoodikaga vastuseid ei saa anda, vaid need küsimused nõuaksid teistsugust metoodikat (nt sisuanalüüsi, küsitlust vms).

Võitlus vähenevate ressursside pärast ning sõjategevuse aktiivistumine 21. saj alguses võib oluliselt sellist uusliberaalse ning konservatiivse ideoloogia tugevnemist toetada. Samas on majandussurutis kahtluse alla pannud uusliberaalse ideoloogia jätkusuutlikkuse, kuna enamikes Lääne ühiskonna riikides on just riiklikud institutsioonid asunud abistama pankrotistumas eraettevõtteid. Seega pole õhukese riigi ideel enam tegelikku kõlapinda ning võib ennustada ideoloogiliste väärtuste ümberhindamist lääne ühiskonnas. Mis suunas see hakkab muutma haridusalaseid diskursusi, on veel vara hinnata.

\section{Kokkuvõte}

Kriitilise diskursusanalüüsi kaudu on võimalik tekstide põhjal uurida, kuidas "loomulikustatakse" ning legitimeeritakse ideoloogilised uskumused hariduse küsimustes. Töös võrreldi hariduspoliitilisi diskursusi Eesti, Sloveenia ning Soome õppekavades ning haridusseadustikes, et hinnata nende rolli sotsiopoliitilises kontekstis juhtiva ideoloogia seadustamisel. Töös otsiti vastust küsimusele, kuivõrd on esindatud sotsiaaldemokraatlik, liberaalne ning konservatiivne ideoloogia ning milliseid sarnasusi ning erinevusi ning milliseid muutusi võib eri ühiskondades täheldada.

Kõige tugevamalt on kolme maa haridusalastes tekstides esindatud konservatiivne, siis liberaalne ning kõige tagasihoidlikumalt esindatud sotsiaaldemokraatlik diskursus, seda eelkõige Eesti tekstides. Kolme maa haridustekste võrreldes tuleb esile see, et Eesti ja Sloveenia haridustekste iseloomustab tugev liberaalse diskursuse osakaal. Eesti ning Soome haridustekstides on tugevnemas konservatiivne diskursus.

Ajalises perspektiivis on liberaalne diskursus nõrgenemas ning konservatiivne tugevnemas. See ühtib sotsiaalteadlaste ning kriitiliste diskursusanalüüsi autorite hinnangutega, mille põhjal 1980-ndatel esile tõusnud uusliberaalne ideoloogia, mis vahetas välja sotsiaaldemokraatliku, on omakorda kaasa toonud konservatiivsete väärtuste tõusu.

\section{Viidatud kirjandus}

Beck, Ulrich 2005. Inequality and recognition: Pan-European social conflicts and their political dynamic. - Anthony Giddens, Patrick Diamond (Eds.). The New Egalitarism. Cambridge: Polity Press, 120-142.

van Dijk, Teun A. 2005. Ideoloogia. Multidistsiplinaarne käsitlus. Tartu: Tartu Ülikooli Kirjastus.

Fairclough, Norman 1992. Discourse and Social Change. Cambridge: Polity Press. 
Fairclough, Norman 1999. Global capitalism and critical awareness of language. - Language Awareness, 8 (2), 71-83. doi:10.1080/09658419908667119

Fairclough, Norman 2005. Critical discourse analysis in transdisciplinary research. R. Wodak, P. Hilton (Eds.). A New Agenda in (Critical) Discourse Analyses. Discourse Approaches to Politics, Society and Culture 13. Amsterdam: John Benjamins, 53-70.

Giddens, Anthony 1998. The Third Way. Cambridge: Polity Press.

Giroux, Henry A. 2004. The Terror of Neoliberalism: Authoritarianism and the Eclipse of Democracy. Garamond Imprint.

Kivirauma, Joel; Rinne, Risto; Seppänen, Piia 2003. Neo-liberal education policy approaching the Finnish shoreline? - Journal for Critical Education Policy Studies, 1 (1), http:// www.jceps.com/index.php?pageID=article\&articleID $=5$ (30.09.08).

Kymlicka, Will 2002. Contemporary Political Philosophy: An Introduction. Oxford, New York: Oxford University Press.

Miliband, Edward 2005. Does inequality matter? - Anthony Giddens, Patrick Diamond (Eds.). The New Egalitarism. Cambridge: Polity Press, 39-51.

Mulderrig, Jane 2003. Consuming education: A critical discourse analysis of social actors in New Labour's education policy. - Journal for Critical Education Policy Studies, 1 (1), http://www.jceps.com/index.php?pageID=article\&articleID=2 (28.12.08).

Nisbet, Robert 1978. Conservatism. - Tom Bottomore, Robert Nisbet (Eds.). A History of Sociological Analysis. London: Heinemann, 80-117.

Scott, Mike 1997. WordSmith Tools. Oxford: Oxford University Press.

Waldron, Jeremy 1993. Liberal Rights. Cambridge: Cambridge University Press.

Katrin Aava (Tallinna Ülikool) uurimisvaldkonnad on meediatekstide analüüs, diskursusanalüüs, haridustekstide analüüs.

aava@tlu.ee 


\section{COMPARATIVE DISCOURSE ANALYSIS OF EDUCATIONAL TEXTS}

\section{Katrin Aava}

Tallinn University

The article studies ideologies dominant at the macro level in society by means of discourses present in educational texts at the micro level. Education policy discourses in major Estonian, Slovenian and Finnish educational texts are compared both in curricula and education legislation, in order to understand their role in the socio-political context in reproducing and legitimising the leading ideology. The article seeks to find out to what relative extent the social democratic, liberal and conservative discourses are represented, what kind of similarities and differences as well as changes can be detected in different societies, and how discourses have changed over time. The results are compared to those reached by various analyses of educational discourses.

The most powerfully represented discourse in educational texts of the three countries is the conservative one, followed by the liberal and the social democratic discourse in that order, the latter being the least represented, especially in Estonia. The conservative discourse is on the increase in Estonian and Finnish educational texts. From a time perspective, the liberal discourse in educational texts is weakening and the conservative one is becoming stronger. The result coincides with the opinion expressed by social scientists and authors of critical discourse analysis, according to which the rise of neoliberal ideology in the 1980s, coming to replace social democratic ideology, has contributed to an increase in conservative values.

Keywords: critical discourse analysis, curriculum, education legislation, ideology, Estonian, Slovenian, Finnish 